\title{
Use of Laminar Flow and Unstirred Layer Models to Predict Intestinal Absorption in the Rat
}

\author{
Michael D. Levitt, Julie M. Kneip, and David G. Levitt \\ Research Service, Veterans Administration Medical Center, Minneapolis, Minnesota 55417; and Departments \\ of Medicine and Physiology, University of Minnesota, Minneapolis, Minnesota 55417
}

\begin{abstract}
Carbon monoxide (CO) and $\left[{ }^{14} \mathrm{C}\right]$ warfarin were used to measure the preepithelial diffusion resistance resulting from poor luminal stirring $\left(\boldsymbol{R}_{\mathrm{L}}\right)$ in the constantly perfused rat jejunum at varying degrees of distension $(0.05,0.1$, and $0.2 \mathrm{ml} / \mathrm{cm}) . R_{L}$ was much greater than epithelial cell resistance, indicating that poor stirring was the limiting factor in absorption and that an appropriate model of stirring should accurately predict absorption. A laminar flow model accurately predicted the absorption rate of both probes at all levels of gut distension, as well as the absorption of glucose when $\boldsymbol{R}_{\mathrm{L}}$ was the rate-limiting factor in absorption. In contrast, an unstirred layer model would not have predicted that gut distension would have little influence on absorption, and would have underestimated $\left[{ }^{14} \mathrm{C}\right.$ warfarin absorption relative to $\mathrm{CO}$. We concluded that in the perfused rat jejunum, laminar flow accurately models luminal stirring and an unstirred layer should be considered to be a unit of resistance in laminar flow, rather than a model of luminal stirring.
\end{abstract}

\section{Introduction}

Intestinal absorption of a solute can be perceived as a two-step process in which the solute must first contact the brush border and then be transported across the epithelial cell (1). Because luminal contents are imperfectly stirred, the fluid adjacent to the mucosa becomes depleted of rapidly absorbed solutes. This fluid then creates a preepithelial diffusion barrier (2), across which more centrally located solutes must diffuse to reach the brush border.

Two models have been used to describe the rate at which material is absorbed from a perfused intestinal loop. The classical "unstirred layer" model (1, 3-6) assumes that the luminal contents can be divided into a perfectly stirred region in the center of the lumen and an unstirred layer at the periphery. The thickness of this unstirred layer is an adjustable parameter that must be determined experimentally. In the second model, "laminar flow" (7-11), it is assumed that the fluid in the lumen has an ideal laminar flow profile with a fluid velocity that is zero at the wall and increases parabolically to a maximum in the center. This velocity profile tends to mix the luminal contents, because solutes at different radial positions are convected axially at different rates, but there is no convective mixing in the radial direction. A major advantage of this model over the classical model is that it provides a complete physical description and does not have adjustable parameters.

Address reprint requests to Dr. Michael D. Levitt, ACOS for Research (151), 54th Street and 48th Avenue South, Minneapolis, MN 55417.

Received for publication 1 May 1987 and in revised form $16 \mathrm{No}$ vember 1987.

The Journal of Clinical Investigation, Inc.

Volume 81, May 1988, 1365-1369
In a previous paper, we tested the accuracy of the laminar flow model by comparing the experimentally determined absorption rate of carbon monoxide (CO) with the theoretical prediction for this model (12). Although good agreement was observed between the laminar flow theory and the experimental observations, this finding did not eliminate the unstirred layer model, because it is always possible to choose an unstirred layer thickness that yields the correct absorption rate. To further test the two models, in the present study we measured the absorption rates of three solutes with different diffusion coefficients in intestinal loops with different radii. Agreement between the theoretical predictions of the laminar flow model and the experimental results for all these different conditions would provide strong evidence against an unstirred layer model, since such a layer should not consistently vary in a manner that absorption always equals that predicted by laminar flow.

\section{Methods}

Perfusion technique. All studies were carried out in male SpragueDawley rats $(250-300 \mathrm{~g})$ anesthetized with pentobarbital.

The intestinal perfusion technique was identical to that previously described (12). Through a midline incision, exactly $30 \mathrm{~cm}$ of upper jejunum (measured with a tape) was isolated between ligatures. We took care to preserve blood flow to the segment. Polyethylene cannulas attached to threeway stopcocks were tied into both ends of this segment, which was then flushed free of debris and gas with isotonic saline. All fluid was then stripped from the segment and the distal stopcock was closed. The test solution $(1.5,3$, or $6 \mathrm{ml})$ was infused into the segment, the distal stopcock was opened, and the segment was then constantly perfused with the test solution via the proximal cannula and aspirated via the distal cannula at a rate of $1.95 \mathrm{ml} / \mathrm{min}$ using a Harvard syringe pump (Harvard Apparatus Co., Inc., The Ealing Corp., S. Natick, MA). After a 10-min equilibration period, three $1.0-\mathrm{ml}$ samples of infusate and perfusate were anaerobically obtained for analysis. At the conclusion of the study, the infusate was switched to isotonic saline and all perfusate flushed out over the ensuing $10 \mathrm{~min}$ was collected and analyzed for $\left[{ }^{3} \mathrm{H}\right]$ polyethylene glycol $\left(\left[{ }^{3} \mathrm{H}\right] \mathrm{PEG}\right) .{ }^{1}$ From knowledge of the $\left[{ }^{3} \mathrm{H}\right] \mathrm{PEG}$ in the segment, the concentration of $\left[{ }^{3} \mathrm{H}\right]-$ PEG on the final sample collected for absorption measurements, and the dead space of the cannulas, it was possible to calculate the volume of fluid in the segment at the end of the absorption study.

The infusate consisted of isotonic saline containing $\mathrm{CO}$ at a PCO of $\sim 100$ Torr $(\sim 0.0016 \mathrm{ml} \mathrm{CO} / \mathrm{ml}), 5.5 \mathrm{~mm}$ glucose $(100 \mathrm{mg} / \mathrm{dl})$, $\left[{ }^{14} \mathrm{C}\right]$ warfarin at a concentration of $13.5 \mu \mathrm{g} / \mathrm{ml}$ and $40,000 \mathrm{dpm} / \mathrm{ml}$, and $\left[{ }^{3} \mathrm{H}\right]$ PEG $(0.1 \mathrm{~g} / \mathrm{dl}$ and $400,000 \mathrm{dpm} / \mathrm{ml})$.

Preliminary studies with warfarin. Lipid/water solubility was determined by adding $0.1 \mu \mathrm{Ci}$ of $\left[{ }^{14} \mathrm{C}\right]$ warfarin to a mixture of $2 \mathrm{ml}$ of $\mathrm{PO}_{4}$-buffered saline ( $\mathrm{pH} \mathrm{7.4)}$ and $2 \mathrm{ml}$ of olive oil. The mixture was stirred vigorously and the $\left[{ }^{14} \mathrm{C}\right]$ warfarin concentrations in the olive oil and saline was assessed at 1,2 , and $4 \mathrm{~d}$. Constant concentrations of $\left[{ }^{14} \mathrm{C}\right]$ warfarin were obtained by $24 \mathrm{~h}$ with an olive oil/saline ratio of $85: 1$.

1. Abbreviations used in this paper: PEG, polyethylene glycol; $R_{\mathrm{EC}}$, resistance of the epithelial cell; $R_{\mathrm{L}}$, resistance due to poor luminal stirring; $R_{\mathrm{T}}$, total resistance. 
To estimate the fraction of absorbed $\left[{ }^{14} \mathrm{C}\right]$ warfarin that would be bound to serum proteins, the following calculations and studies were performed. The increment in plasma warfarin concentration that would occur during passage of blood through the villi of the perfused segment was calculated as follows. The plasma flow to the villi of the $30-\mathrm{cm}$ segment of rat jejunum was estimated to be $\sim 0.9 \mathrm{ml} / \mathrm{min}$, based on: (a) the perfusion rate of the intestine, which equaled $1.5 \mathrm{ml} / \mathrm{g}$ per min (13), (b) a gut weight of $0.07 \mathrm{~g} / \mathrm{cm}$ (personal observation), (c) the villi receiving $50 \%$ of flow to the segment (14), and $(d)$ a hematocrit of $40 \%$. The mean absorption rate of warfarin was $\sim 3.6 \mu \mathrm{g} / \mathrm{min}$, yielding an increment in villus plasma warfarin concentration of $\sim 4$ $\mu \mathrm{g} / \mathrm{ml}$ as blood perfused the villi. Assuming a volume of distribution of warfarin of $7.5 \%$ of body weight and no warfarin metabolism, at the end of a 60 -min study the plasma warfarin concentration would be $\sim 9.7 \mu \mathrm{g} / \mathrm{ml}$. Equilibrium dialysis studies were carried out at $37^{\circ} \mathrm{C}$ on samples of rat plasma or saline containing warfarin concentrations of $0.95,11$, and $173 \mu \mathrm{g} / \mathrm{ml}$, values encompassing the maximal levels expected in our studies. $1 \mathrm{ml}$ of plasma or saline containing the above concentrations of warfarin was dialyzed to equilibrium against $9 \mathrm{ml}$ of saline for $4 \mathrm{~d}$. Warfarin in saline equilibrated nearly perfectly. The percentage binding of warfarin by rat plasma was 98,97 , and $92 \%$ at concentrations of $0.95,11$, and $173 \mu \mathrm{g} / \mathrm{ml}$ of warfarin, respectively. These binding values are in agreement with studies of human plasma showing $>98 \%$ protein binding of therapeutic warfarin doses using equilibrium dialysis $(15,16)$, HPLC (17), or ultrafiltration (18). Thus, nearly all plasma warfarin would be bound at the concentrations achieved in our study.

The nonsaturated nature of $\left[{ }^{14} \mathrm{C}\right]$ warfarin absorption at the concentrations employed in our studies was confirmed by measuring the absorption of $\left[{ }^{14} \mathrm{C}\right]$ warfarin at warfarin concentrations of 13.5 and $121.5 \mu \mathrm{g} / \mathrm{ml}$, and a perfusion rate of $1.95 \mathrm{ml} / \mathrm{min}$ in a gut distended with $0.1 \mathrm{ml} / \mathrm{cm}$ of gut. In three studies, the percentage absorptions averaged, respectively, 14.3 and $15.1 \%$ for the lower and higher warfarin concentrations, indicating no saturation of transport. All subsequent studies were carried out at the lower warfarin concentration.

Analyses. The concentration of $\mathrm{CO}$ in infusate and perfusate was determined by gas chromatography. 1-ml aliquots of infusate or perfusate and $50 \mathrm{ml}$ of CO-free argon in a syringe were shaken vigorously for $1 \mathrm{~min}$. (Analysis of liquid and gas showed that $>99 \%$ of the $\mathrm{CO}$ was in the gas phase.) We then analyzed the argon for $\mathrm{CO}$ content, using a gas chromatograph employing a $3^{\prime} \times 3 / 16^{\prime \prime}$ column packed with a molecular sieve, an oven temperature of $100^{\circ} \mathrm{C}$, argon as the carrier gas $(40 \mathrm{ml} / \mathrm{min}$ ), and a reduction detector (Trace Analytical, Stanford, CA).

The concentrations of $\left[{ }^{3} \mathrm{H}\right] \mathrm{PEG}$ and $\left[{ }^{14} \mathrm{C}\right]$ warfarin were determined by liquid scintillation counting with appropriate corrections for quenching and crossover. Glucose concentration was determined using the glucose oxidase technique.

Calculations. The percentage absorption of $\mathrm{CO}$, glucose, and $\left[{ }^{14} \mathrm{C}\right]$ warfarin was determined by difference, using standard absorption equations for constant perfusion studies (19). The clearance (corrected for gradient) of each of these solutes was then calculated from:

Clearance $=($ fraction absorbed $) \cdot($ infusion rate $) \cdot(C / \bar{C})$,

where $\bar{C}$ equals the logarithmic mean solute concentration and $C$ is the concentration infused. $\bar{C} / C$ was calculated from (20):

$\bar{C} / C=\left[\left(C_{\text {perfusate }} / C_{\text {infusate }}\right)-1\right] / \ln \left(C_{\text {perfusate }} / C_{\text {infusate }}\right)$.

The value for clearance (milliliters per minute) was normalized for the length of the gut segment $(30 \mathrm{~cm})$ to yield clearance per centimeter with units of square centimeters per minute.

The total resistance to absorption $\left(R_{\mathrm{T}}\right)$ per centimeter of gut equals the reciprocal of clearance per centimeter:

$R_{\mathrm{T}}=1 /$ (clearance $\left./ \mathrm{cm}\right)$.

$R_{\mathrm{T}}$ consists of two resistances in series, a preepithelial diffusion resistance resulting from poor luminal stirring $\left(R_{\mathrm{L}}\right)$ and the resistance of the epithelial cell $\left(R_{\mathrm{EC}}\right)$ :
$R_{\mathrm{T}}=1 /($ clearance $/ \mathrm{cm})=R_{\mathrm{EC}}+R_{\mathrm{L}}$,

$R_{\mathrm{L}}=R_{\mathrm{T}}-R_{\mathrm{EC}}$.

In a previously published paper (21), we found (via measurement of $\mathrm{CO}$ absorption from a gaseous infusate) that $\boldsymbol{R}_{\mathrm{EC}}$ per centimeter of gut for a $30-\mathrm{cm}$ segment of rat jejunum distended with $0.1 \mathrm{ml} / \mathrm{cm}$ was $4.8 \mathrm{~min} / \mathrm{cm}^{2}$. Assuming that epithelial cell thickness remains constant, the resistance of the epithelium should be proportional to surface area and the $R_{\mathrm{EC}}$ for $\mathrm{CO}$ at gut volumes of 0.05 and $0.20 \mathrm{ml} / \mathrm{cm}$ will be 6.8 and $3.4 \mathrm{~min} / \mathrm{cm}^{2}$, respectively. Thus, $R_{\mathrm{L}}$ for $\mathrm{CO}$ was calculated from the $R_{\mathrm{T}}$ measured for each experiment and $R_{\mathrm{EC}}$ determined from studies of $\mathrm{CO}$ absorption from argon.

$R_{\mathrm{EC}}$ cannot be measured directly for $\left[{ }^{14} \mathrm{C}\right]$ warfarin or glucose. In the concentration range used in this study, $\left[{ }^{14} \mathrm{C}\right]$ warfarin is passively absorbed (like $\mathrm{CO}$ ), has a very high lipid/water solubility of roughly $80: 1$, and is almost entirely bound to plasma protein in the blood (see preliminary studies). Therefore, we concluded that warfarin absorption is comparable to $\mathrm{CO}$ absorption in that $(a)$ the gradient driving this passive absorption is the brush border solute concentration, $(b)$ the membrane would offer negligible resistance to warfarin absorption, and $(c)$ the epithelial cell barrier to warfarin absorption should be the same thickness of cell water that provides the barrier to $\mathrm{CO}$ absorption. It was further assumed that the ratio of the diffusion coefficients of warfarin and $\mathrm{CO}$ in cell water were proportional to the ratio of their free aqueous diffusion coefficients $(D)$. Thus, using the experimental value of $D$ for $C O\left(2.7 \times 10^{-5} \mathrm{~cm}^{2} / \mathrm{s}\right)(22)$ and a $D$ for warfarin of 7.2 $\times 10^{-6} \mathrm{~cm}^{2} / \mathrm{s}$ (estimated from the $D$ of glucose [23] and the assumption that $D$ varies inversely as the cube root of molecular weight), we obtained an $R_{\mathrm{EC}}$ for warfarin of $18 \mathrm{~min} / \mathrm{cm}^{2}$ at a gut distension of 0.1 $\mathrm{ml} / \mathrm{cm}$.

The possibility that appreciable warfarin diffusion occurred across the cell via lipid membranes (as opposed to the aqueous phase) seems unlikely based on the following reasoning. Diffusion in biological membranes is 30 to 100 times less rapid than in water (24). Thus, even though warfarin has a high lipid/aqueous solubility of 80 , the diffusivity (solubility $X$ diffusion coefficient) of warfarin in biological membrane lipid is roughly comparable to that in water. Only a small fraction $(\sim 2.5 \%)$ of the cell is membrane lipid. If all the membrane lipid were arranged in a single continuous band across the cell, only $\sim 2.5 \%$ of warfarin would be conducted by this pathway. Since most membrane lipid is in discrete, discontinuous organelles, even with a very high lipid diffusivity, the aqueous region would be the limiting factor for warfarin absorption.

Models of luminal stirring. Luminal stirring is commonly modeled in terms of the thickness of a layer of totally unstirred luminal fluid overlaying the mucosa (which would yield the observed $R_{\mathrm{L}}$ ), while the more centrally located fluid is assumed to be perfectly stirred. To calculate the thickness of this unstirred layer from $R_{\mathrm{L}}$, it is necessary to define its surface area, which should be the surface area of a smooth cylinder that has the internal dimensions of the gut segment. If $R_{\mathrm{L}}$ is expressed in the terms of resistance per square centimeters of surface area, the thickness of unstirred layer $\left(T_{\mathrm{UL}}\right)$ is calculated as follows:

$T_{\mathrm{UL}}=R_{\mathrm{L}} D$.

A second model of luminal stirring assumes that perfused luminal fluid moves with laminar flow. A number of investigators have described mathematical solutions for the rate of solute or heat transfer to the outer surface of a cylindrical body of fluid moving with laminar flow (7-11). Knowledge of the permeability of the tube (i.e., the gut epithelium) holding this fluid allows prediction of the rate of transfer of solute across the tube wall. We have previously described in detail the approach used to solve the appropriate differential equations by the finite difference technique (12). The fraction of a solute absorbed from an intestinal segment is a function of two dimensionless variables. The first represents the rate of axial convection relative to the rate of radial diffusion and is commonly known as the Graetz number (GZ).

$G Z=\pi D L / 2 F$, 
Table I. Resistances to Absorption of CO, $\left[{ }^{14} \mathrm{C}\right]$ Warfarin, and Glucose at Varying Degrees of Gut Distension

\begin{tabular}{|c|c|c|c|c|c|c|c|c|}
\hline Probe & $n$ & Gut volume & Absorption & Clearance per centimeter & $R_{\mathrm{T}}$ & $R_{\mathrm{BC}}$ & $\boldsymbol{B}_{\mathrm{L}}$ & Unstirred layer \\
\hline & & $\mathrm{ml} / \mathrm{cm}$ & $\% / 30 \mathrm{~cm}$ & $\mathrm{~cm}^{2} / \min$ & & $\min / \mathrm{cm}^{2}$ & & $\mu m$ \\
\hline \multirow[t]{3}{*}{$\mathrm{CO}$} & (5) & 0.05 & $34 \pm 2$ & $0.027 \pm 0.002$ & $37 \pm 2$ & 6.8 & $30 \pm 2$ & $387 \pm 26$ \\
\hline & (8) & 0.10 & $31 \pm 2$ & $0.024 \pm 0.002$ & $44 \pm 3$ & 4.8 & $39 \pm 3$ & $711 \pm 56$ \\
\hline & (5) & 0.20 & $35 \pm 1$ & $0.028 \pm 0.001$ & $35 \pm 1$ & 3.4 & $32 \pm 1$ & $820 \pm 29$ \\
\hline \multirow[t]{3}{*}[{}^{14}\mathrm{C}]{$\mathrm{War}$} & (5) & 0.05 & $12 \pm 1$ & $0.0089 \pm 0.0007$ & $115 \pm 10$ & 26 & $89 \pm 10$ & $304 \pm 33$ \\
\hline & (8) & 0.10 & $14 \pm 2$ & $0.0094 \pm 0.0012$ & $119 \pm 15$ & 18 & $101 \pm 15$ & $486 \pm 71$ \\
\hline & (5) & 0.20 & $13 \pm 1$ & $0.0093 \pm 0.0004$ & $109 \pm 9$ & 13 & $96 \pm 5$ & $655 \pm 37$ \\
\hline \multirow[t]{3}{*}{ Glucose } & (5) & 0.05 & $16 \pm 1$ & $0.011 \pm 0.001$ & $100 \pm 9$ & & & \\
\hline & (8) & 0.10 & $15 \pm 2$ & $0.010 \pm 0.001$ & $105 \pm 12$ & & & \\
\hline & (5) & 0.20 & $16 \pm 1$ & $0.012 \pm 0.001$ & $93 \pm 5$ & & & \\
\hline
\end{tabular}

where $D$ is the aqueous diffusion coefficient, $L$ is length of the gut segment, and $F$ is the perfusion rate. The Graetz number is determined by the time required for fluid flowing in the center of the lumen to traverse the gut $\left(\pi r^{2} L / 2 F\right)$, divided by the time required for a solute in the center of the lumen to diffuse out to the brush border $\left(r^{2} / D\right)$. Note that radius ( $r$ ) cancels out and the Graetz number is independent of radius.

The second variable is $k$, which is defined by:

$k=(D / r) / P_{\mathrm{w}}=(D / r)(D \mathrm{w} / d)$

where $D$ is the diffusion coefficient in the lumen, $r$ is the radius of the loop, $P_{w}$ is the permeability of the epithelial cell, and $d$ is the thickness of the epithelial cell. The second equality in Eq. 8 comes from defining $P_{\mathrm{w}}$ in terms of the diffusion coefficient in the epithelial cell $\left(D_{\mathrm{w}}\right)$ and thickness $(d)$ of the epithelial cell. For $\mathrm{CO}$, the value of $\boldsymbol{P}_{\mathrm{w}}$ was experimentally determined by measuring the rate of $\mathrm{CO}$ absorption from a gas-filled loop, a situation in which intraluminal mixing is nearly infinitely rapid and absorption is limited only by epithelial cell permeability (21). From our previous measurements of $\mathrm{CO}$ absorption from a gas-filled lumen distended with $0.1 \mathrm{ml} / \mathrm{cm}$, we determined $P_{\mathrm{w}}$ and, from Eq. 8, a corresponding $k$ of 0.05 . Using estimates of $R_{\mathrm{EC}}$ for a loop distended with $0.05 \mathrm{ml} / \mathrm{cm}$ and $0.20 \mathrm{ml} / \mathrm{cm}$ yields corresponding $k$ 's of 0.07 and 0.035 , respectively. Assuming that the $R_{\mathrm{EC}}$ of warfarin relative to $\mathrm{CO}$ scales as the bulk diffusion coefficient, warfarin should have the same values of $k$ as CO. Since both the Graetz number and $k$ are known for our experiments, the fractional absorption of $\mathrm{CO}$ and $\left[{ }^{14} \mathrm{C}\right]$ warfarin should be predictable if luminal fluid is moving with laminar flow.

\section{Results}

Volume of fluid in gut. Comparison of the concentration of $\left[{ }^{3} \mathrm{H}\right] \mathrm{PEG}$ in infusate and perfusate indicated only minor secretion or absorption of fluid during the course of the study. The volume of fluid calculated to be present in the gut at the end of the study averaged ( \pm 1 SEM) $1.5 \pm 0.1,3.3 \pm 0.2$, and $6.0 \pm 0.3 \mathrm{ml}$, when the initial instilled volume was $1.5,3.0$, and $6.0 \mathrm{ml}$, respectively.

The results of absorption studies are summarized in Table I. Increasing distension of the lumen from 0.05 to $0.2 \mathrm{ml} / \mathrm{cm}$ of gut did not significantly alter the percentage absorption rates of $\mathrm{CO},\left[{ }^{14} \mathrm{C}\right]$ warfarin, or glucose (see Fig. 1). Because the infusion rate was fixed at $1.95 \mathrm{ml} / \mathrm{min}$, the absolute absorption rates, clearance of the probes, and $R_{\mathrm{T}}$ also did not change significantly over the fourfold range of gut distension. Lastly, since the vast majority of $R_{\mathrm{T}}$ results from poor luminal stirring, $R_{\mathrm{L}}$ was not significantly altered by the fourfold increase in gut distension. $R_{\mathrm{L}}$ represented the bulk of the resistance in all studies and, thus, poor luminal stirring was the rate-limiting step in absorption.
The predicted influence of gut distension on percent absorption of $\mathrm{CO}$ from fluid moving with laminar flow is shown in Fig. 2. In this figure, predicted absorption is plotted against Graetz number for four values of $k: 0.00$, the value for an infinitely permeable epithelium; 0.05 , the value measured for a gut segment distended with $0.1 \mathrm{ml} / \mathrm{cm}$; and 0.035 and 0.070 , values of $k$ expected when the gut is distended with 0.05 and $0.20 \mathrm{ml} / \mathrm{cm}$, respectively. It is apparent that with laminar flow only minimal alterations in absorption rate would be expected to result from this varying distension of the gut segment. The arrows in Fig. 2 indicate the Graetz numbers for the solutes used in our experiments and the points represent the observed percentage absorption. For both $\mathrm{CO}$ and $\left[{ }^{14} \mathrm{C}\right]$ warfarin, the observed absorption rates were close to those predicted for laminar flow. The observed absorption rates for glucose were compatible with laminar flow at low values for $k$ in the range of 0.05 .

\section{Discussion}

The purpose of these experiments was to determine which of two models, an unstirred layer or laminar flow, provides a better description of absorption from the perfused rat jejunum. To test the models, ideally, one would like to use a solute whose absorption rate is limited entirely by intraluminal mixing, i.e., a solute with infinite mucosal permeability. Short of this ideal, one should choose solutes that $(a)$ have a sufficiently high mucosal permeability so that intraluminal mixing is the dominant factor in absorption and $(b)$ have a known mucosal permeability so that this small contribution can be corrected quantitatively.

Three solutes were used in the present experiments: $\mathrm{CO}$, glucose, and warfarin. CO comes closest to the ideal solute. This gas is tightly bound to hemoglobin, so that counter current exchange (25) is negligible and its free concentration in

co

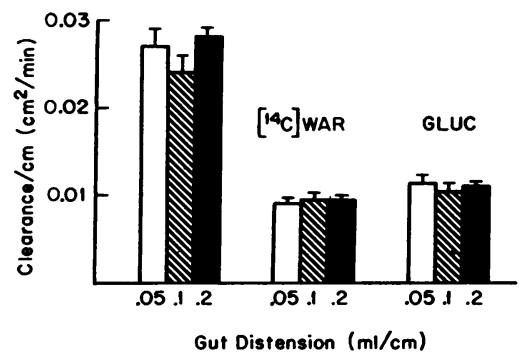

Figure 1. Clearance per centimeter (mean \pm 1 SEM) of $\mathrm{CO},\left[{ }^{14} \mathrm{C}\right]-$ warfarin, and glucose at varying degrees of gut distension. A fourfold increase in distension did not significantly alter the clearance of these compounds. 


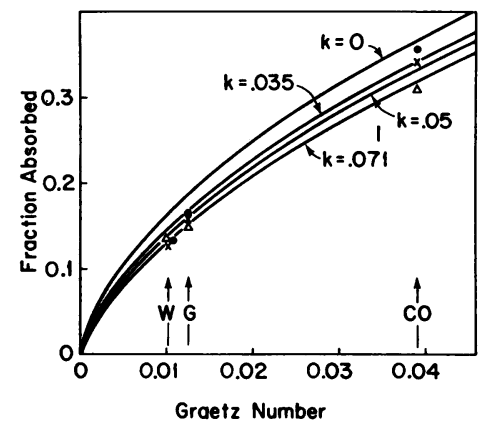

Figure 2. Plot of predicted fractional absorption against Graetz number for varying $k$ values (epithelial cell resistance relative to luminal resistance). A $k$ of 0 represents infinite permeability. $0.035,0.05$, and 0.071 represent, respectively, the $k$ values of $\mathrm{CO}$ and $\left[{ }^{14} \mathrm{C}\right]$ warfarin for segments distended with 0.05 , 0.1 , and $0.2 \mathrm{ml}$ of saline

per centimeter. The arrows indicate the Graetz numbers of warfarin (W), glucose (G), and CO. The symbols indicate the observed mean absorption rates at distensions of $0.05 \mathrm{ml} / \mathrm{cm}(\times), 0.10 \mathrm{ml} / \mathrm{cm}(\Delta)$, and $0.20 \mathrm{ml} / \mathrm{cm} \mathrm{(o)}$

the blood is negligible. Since $\mathrm{CO}$ has a high lipid solubility, the cell membrane is not a permeability barrier and mucosal permeability should be determined by the thickness of epithelial cell water. The most important advantage of $\mathrm{CO}$ is that $R_{\mathrm{EC}}$ can be experimentally determined by measuring the rate of $\mathrm{CO}$ absorption from the gas-filled lumen (21), a case equivalent to having perfect luminal mixing.

Glucose and warfarin were also investigated because we wanted to test the models with other solutes that have smaller diffusion coefficients, more in the range of solutes of physiological interest. The $R_{\mathrm{EC}}$ of warfarin and glucose cannot be measured directly. Warfarin was used because its high lipid solubility should reduce membrane resistance to negligible levels relative to the roughly 10,000 -fold thicker aqueous portion of the cell. In addition, warfarin has a high affinity for plasma proteins and, as with $\mathrm{CO}$, the free warfarin concentration in the blood will be maintained near zero. Warfarin absorption thus should be limited by diffusion through the same cell water thickness that determines the resistance of the epithelial cell to $\mathrm{CO} ; \boldsymbol{R}_{\mathrm{EC}}$ for warfarin was calculated from that of $\mathrm{CO}$ based on the relative aqueous diffusion constants of these two solutes.

While epithelial permeability of glucose is not known in our studies; it has been demonstrated that the apparent $K_{\mathrm{m}}$ of rat jejunum perfused in vivo is roughly six times greater than the true $K_{\mathrm{m}}$ determined in vitro (26). This difference results from imperfect luminal stirring in in vivo studies and indicates that at low concentrations of glucose, luminal resistance is the rate-limiting step in absorption.

When the gut was distended with $0.1 \mathrm{ml}$ saline $/ \mathrm{cm}$ length, the clearances per centimeter of $\mathrm{CO}$ and $\left[{ }^{14} \mathrm{C}\right]$ warfarin were 0.024 and $0.0094 \mathrm{~cm}^{2} / \mathrm{min}$, respectively. Halving or doubling the distension of the gut did not significantly alter these clearance rates (see Table I and Fig. 1). Luminal resistance provided $80-90 \%$ of the total resistance in all studies.

Laminar flow is a mathematical construct from which absorption rates can be predicted, a priori, from knowledge of the Graetz number, a measure of convection axial to radial diffusion, and $k$, a variable that reflects epithelial resistance relative to luminal resistance (8). Since both the Graetz number and the nearly negligible $k$ of $\sim 0.05$ are known in our experiments, the validity of this laminar flow model can be tested by comparison of observed absorptions with those predicted by laminar flow. As shown in Fig. 2, the agreement between predicted and observed absorption rates for $\mathrm{CO}$ and $\left[{ }^{14} \mathrm{C}\right]$ warfarin was excellent at all levels of gut distension. It should be em- phasized that the resistance of the epithelial cell is so small that sizable errors in our calculation of the $\boldsymbol{R}_{\mathrm{EC}}$ would not appreciably influence the excellent agreement between experimental results and theoretical prediction. For example, if $\boldsymbol{R}_{\mathrm{EC}}$ to $\left[{ }^{14} \mathrm{C}\right]$ warfarin was overestimated by $50 \%$, due to diffusion in lipid, the calculated $R_{\mathrm{L}}$ would increase by only $7-14 \%$, an alteration that would not influence the interpretation of this study.

As shown in Fig. 1, varying levels of gut distension had no significant effect on the rate of absorption of the probes. The Graetz number is independent of gut radius. However, changes in loop distension would alter $k$. This effect was estimated by assuming that increasing distension alters the radius of the loop $(r)$ in Eq. 8 but has no effect on epithelial cell thickness. Loops distended with $0.05 \mathrm{ml} / \mathrm{cm}$ and $0.20 \mathrm{ml} / \mathrm{cm}$ would have corresponding $k$ 's of 0.07 and 0.035 , respectively. The predicted absorption rates for these values of $k$ are also shown in Fig. 2. It can be seen that only very small variations in absorption rate are predicted for the different values of loop distension. Thus, the laminar flow model accurately predicts that distension would have little influence on the absorption rate of our probes.

We are aware of only one other constant infusion study in which gut diameter was varied while other factors were held constant (27). The absorption from a 6-cm segment of rat jejunum was measured at gut diameters of 3.4 and $6.2 \mathrm{~mm}$, values roughly corresponding to our distensions of 0.05 and $0.20 \mathrm{ml} / \mathrm{cm}$ of gut. In contrast to our results, the absorption of aminopyrine, salicylic acid, and phenylalanine roughly doubled with increasing distension, a finding that is incompatible with the concept that flow was laminar and $R_{L}$ was the ratelimiting step in absorption. There are many possible explanations for this result. Turbulence occurring at the inflow and outlet sites would have a much greater influence on absorption in a $6-\mathrm{cm}$ segment than our $30-\mathrm{cm}$ segment. Second, in laminar flow, the brush border concentration of a rapidly absorbed solute falls sharply as fluid moves down the segment. Epithelial permeability limits absorption at the infusion site and $\boldsymbol{R}_{\mathbf{L}}$ becomes increasingly important as the perfusate moves away from the infusion site. Thus, epithelial permeability would have a much greater influence on absorption in a $6-\mathrm{cm}$ than in a 30-cm segment. Distension, which would increase epithelial surface area and, hence, permeability, might have an appreciable effect on absorption in a short segment. Lastly, minor degrees of radial convection at the very slow perfusion rate employed $(0.1 \mathrm{ml} / \mathrm{min}$ vs. $1.95 \mathrm{ml} / \mathrm{min}$ in our study) would produce much greater changes in brush border solute concentration than would faster perfusion rates.

In contrast to laminar flow, the unstirred layer model does not permit a priori prediction of absorption rate whereby the validity of the model can be tested. Rather, a thickness of this putative layer is adjusted to fit the measured absorption rate of a probe. Since the resistance of an unstirred layer is proportional to its surface area/thickness, in our experiments the thickness would have had to exactly doubled, with the fourfold distension to counteract the doubling of the surface area gut.

If the unstirred layer model is correct, there should exist a physical layer of water whose thickness does not depend upon the substrate used to measure the layer. In fact, the experimental thickness of this layer for $\left[{ }^{14} \mathrm{C}\right]$ warfarin was $\sim 30 \%$ less than for CO. In laminar flow, resistance results from depletion of solute from the peripheral layer of the lumen. This depletion occurs more rapidly for small molecules (with larger diffusion 
coefficients) than for bigger molecules (12). Thus, the laminar flow correctly predicts that the smaller molecule, $\mathrm{CO}$, will encounter an apparently thicker "unstirred layer" than does $\left[{ }^{14} \mathrm{C}\right]$ warfarin.

Although epithelial cell resistance for glucose was not known in our experiments, this value should be a small fraction of the total resistance to absorption (20). As shown in Fig. 2, like $\mathrm{CO}$ and $\left[{ }^{14} \mathrm{C}\right]$ warfarin absorption, glucose absorption was accurately predicted by the laminar flow model at all levels of distension when the resistance of the epithelial cell was a small fraction of total resistance, i.e., a $k$ value of $\sim 0.05$.

Thus, the laminar flow model provides a complete theory for predicting absorption from the perfused rat jejunum. There are no parameters (such as the unstirred layer thickness) that need to be adjusted to fit the experimental results. As the above analysis shows, the laminar flow theory quantitatively predicts both the magnitude of absorption and how the absorption varies for solutes with different diffusion coefficients and at different values of loop distension. In contrast, although it is always possible to find an "effective" unstirred layer thickness that can explain the experimental results, this thickness does not have the experimental properties that one would expect for a true physical unstirred layer.

The modeling of luminal resistance as an unstirred layer leads to erroneous predictions. For example, one would predict that with an unstirred layer, $R_{\mathrm{L}}$ is constant per centimeter length of gut and that this resistance is inversely proportional to the aqueous diffusion coefficient of the solute. In actuality, in laminar flow luminal resistance increases with gut length and luminal resistance is less than inversely proportional to the diffusion coefficient of solutes.

We conclude that an unstirred layer should not be considered a model of luminal stirring in the perfused rat jejunum, but rather an empirical unit of resistance, i.e., the thickness of a water layer that would yield the resistance in laminar flow for a given probe. Additional experiments will be required to determine if laminar flow adequately represents luminal stirring in a more physiologic situation in nonlaparotomized animals or in animals with more muscular intestinal tracts that might induce better stirring of luminal contents.

\section{Acknowledgments}

This work was supported in part by the Veterans Administration and the National Institutes of Health.

\section{References}

1. Westergaard, H., and J. M. Dietschy. 1974. Delineation of the dimensions and permeability characteristics of the two major diffusion barriers to passive mucosal uptake in the rabbit intestine. J. Clin. Invest. 54:718-732.

2. Winne, D. 1984. Unstirred layer as a diffusion barrier in vitro and in vivo. In Intestinal Absorption and Secretion. E. Skadhaue and K. Heintze, editors. MTP Press, Lancaster, UK. 21-38.

3. Westergaard, H., K. H. Holtermuller, and J. M. Dietschy. 1986. Measurement of resistance of barriers to solute transport in vivo in rat jejunum. Am. J. Physiol. 250:G727-G735.

4. Thomson, A. B. 1985. Intestinal uptake of fatty acids, cholesterol and decanol in ileal resected rabbits: effect of Isocal and Portagen. Comp. Biochem. Physiol. A. Comp. Physiol. 82:819-826.

5. Harris, M. S., J. W. Dobbins, and H. J. Binder. 1986. Augmentation of neutral sodium chloride absorption by increased flow rate in rat ileum in vivo. J. Clin. Invest. 78:431-438.
6. Smithson, K. W., D. B. Millar, L. R. Jacobs, and G. M. Gray. 1981. Intestinal diffusion barrier: unstirred water layer or membrane surface mucous coat? Science (Wash. DC). 214:1241-1244.

7. Winne, D., and I. Markgraf. 1979. The longitudinal intraluminal concentration gradient in the perfused rat jejunum and the appropriate mean concentration for calculation of the absorption rate. NaunynSchmiedeberg's Arch. Pharmacol. 309:271-279.

8. Amidon, G. L., J. Kou, R. L. Elliott, and E. N. Lightfoot. 1980. Analysis of models for determining intestinal wall permeabilities. $J$. Pharm. Sci. 69:1369-1373.

9. Elliott, R. L., G. L. Amidon, and E. N. Lightfoot. 1980. A convective mass transfer model for determining intestinal wall permeabilities: laminar flow in a circular tube. J. Theor. Biol. 87:757-771.

10. Miyamoto, Y., M. Hanano, T. Iga, and M. Ishikawa. 1982. A drug absorption model of the intestinal tract based on the two-dimensional laminar flow in a circular tube. J. Pharmacobio-dyn. 5:445-447.

11. Yuasa, H., Y. Miyamoto, T. Iga, and M. Hanano. 1984. A laminar flow absorption model for a carrier-mediated transport in the intestinal tract. J. Pharmacobio-dyn. 7:604-606.

12. Levitt, M. D., C. A. Fetzer, J. M. Kneip, J. H. Bond, and D. G. Levitt. 1987. Quantitative assessment of luminal stirring in the perfused small intestine of the rat. Am. J. Physiol. 252:G325-G332.

13. Granger, D. N., S. L. Harper, R. J. Korthuis, H. G. Bohlen, and P. R. Kvietys. 1985. Intestinal vasoregulation in spontaneously hypertensive rats. Am. J. Physiol. 249:G786-G791.

14. Bond, J. H., and M. D. Levitt. 1979. Use of microspheres to measure small intestinal villus blood flow in the dog. Am. J. Physiol. 236:E577-E583.

15. O'Reilly, R. A., and D. A. Goulart. 1981. Comparative interaction of sulfinpyrazone and phenylbutazone with racemic warfarin: alteration in vivo of free fraction of plasma warfarin. J. Pharmacol. Exp. Ther. 219:691-694.

16. Larsen, F. G., C. G. Larsen, P. Jakobsen, and R. Brodersen. 1985. Interaction of warfarin with human serum albumin: a stoichiometric description. Mol. Pharmacol. 27:263-270.

17. Sun, S. F., S. W. Kuo, and R. A. Nash. 1984. Study of binding of warfarin to serum albumins by high performance liquid chromatography. J. Chromatogr. 288:377-388.

18. Mungall, D., Y. Y. Wong, R. L. Talbert, M. H. Crawford, J. Marshall, D. W. Hawkins, and T. M. Ludden. 1984. Plasma protein binding of warfarin: methodological considerations. J. Pharm. Sci. 73:1000-1001.

19. Cooper, H., R. Levitan, J. S. Fordtran, and F. J. Ingelfinger. 1966. A method for studying absorption of water and solute from the human small intestine. Gastroenterology. 50:1-7.

20. Riggs, D. S. 1963. The mathematical approach to physiological problems. Williams \& Wilkins, Baltimore, MD. 162-163.

21. Levitt, M. D., T. Aufderheide, C. A. Fetzer, J. H. Bond, and D. G. Levitt. 1984. Use of carbon monoxide to measure luminal stirring in the rat gut. J. Clin. Invest. 74:2056-2064.

22. Altman, P. L., and D. S. Dittmer. 1971. Respiration and Circulation: Biologic Handbook. FASEB, Bethesda, MD.

23. Longsworth, L. G. 1954. Temperature dependence of diffusion in aqueous solutions. J. Phys. Chem. 770-773.

24. Finkelstein, A. 1976. Water and nonelectrolyte permeability of lipid bilayer membranes. J. Gen. Physiol. 68:127-135.

25. Kampp, M., O. Lundgren, and N. Nilsson. 1968. Extravascular shunting of oxygen in the small intestine of the cat. Acta Physiol. Scand. 72:396-403.

26. Yuasa, H., Y. Miyamoto, T. Iga, and M. Hanano. 1986. Determination of kinetic parameters of a carrier-mediated transport in the perfused intestine by two-dimensional laminar flow model: effects of the unstirred water layer. Biochim. Biophys. Acta. 856:219-230.

27. Winne, D. 1979. Rat jejunum perfused in situ: effect of perfusion rate and intraluminal radius on absorption rate and effective unstirred layer thickness. Naunyn-Schmiedeberg's Arch. Pharmacol. 307:265-274. 